\title{
Clinical and molecular basis of hepatocerebral mitochondrial DNA depletion syndrome in Japan: evaluation of outcomes after liver transplantation
}

Masaru Shimura', Naomi Kuranobu², Minako Ogawa-Tominaga', Nana Akiyama', Yohei Sugiyama', Tomohiro Ebihara', Takuya Fushimi' ${ }^{1}$ Keiko Ichimoto ${ }^{1}$, Ayako Matsunaga', Tomoko Tsuruoka' ${ }^{1}$, Yoshihito Kishita ${ }^{3}$, Shuichiro Umetsu', Ayano Inui ${ }^{4}$, Tomoo Fujisawa ${ }^{4}$, Ken Tanikawa ${ }^{5}$, Reiko Ito ${ }^{6}$, Akinari Fukuda7, Jun Murakami ${ }^{2}$, Shunsaku Kajii, Mureo Kasahara ${ }^{7}$, Kazuo Shiraki ${ }^{2}$, Akira Ohtake ${ }^{9,10}$, Yasushi Okazaki ${ }^{3}$ and Kei Murayama ${ }^{1 *}$ (D)

\begin{abstract}
Background: Hepatocerebral mitochondrial DNA depletion syndrome (MTDPS) is a disease caused by defects in mitochondrial DNA maintenance and leads to liver failure and neurological complications during infancy. Liver transplantation (LT) remains controversial due to poor outcomes associated with extrahepatic symptoms. The purposes of this study were to clarify the current clinical and molecular features of hepatocerebral MTDPS and to evaluate the outcomes of LT in MTDPS patients in Japan.
\end{abstract}

Results: We retrospectively assessed the clinical and genetic findings, as well as the clinical courses, of 23 hepatocerebral MTDPS patients from a pool of 999 patients who were diagnosed with mitochondrial diseases between 2007 and 2019. Causative genes were identified in 18 of 23 patients: MPV17 $(n=13), \operatorname{DGUOK}(n=3), \operatorname{POLG}(n=1)$, and MICOS13 $(n=1)$. Eight MPV17-deficient patients harbored c.451dupC and all three DGUOK-deficient patients harbored c.143-307_170del335. The most common initial manifestation was failure to thrive $(n=13,56.5 \%)$. The most frequent liver symptom was cholestasis ( $n=21,91.3 \%$ ). LT was performed on 12 patients, including nine MPV17-deficient and two DGUOK-deficient patients. Among the 12 transplanted patients, five, including one with mild intellectual disability, survived; while seven who had remarkable neurological symptoms before LT died. Five of the MPV17-deficient survivors had either c.149G > A or c.293C > T.

Conclusions: MPV17 was the most common genetic cause of hepatocerebral MTDPS. The outcome of LT for MTDPS was not favorable, as previously reported, however, patients harboring MPV17 mutations associated with mild phenotypes such as C.149G > A or c.293C > T, and exhibiting no marked neurologic manifestations before LT, had a better prognosis after LT.

Keywords: MPV17, DGUOK, POLG, MICOS13, Liver transplantation, Mitochondrial disease, Mitochondrial DNA maintenance defects

\footnotetext{
* Correspondence: kmuraya@mri.biglobe.ne.jp

${ }^{1}$ Center for Medical Genetics, Department of Metabolism, Chiba Children's

Hospital, 579-1 Heta-cho, Midori-ku, Chiba 266-0007, Japan

Full list of author information is available at the end of the article
}

(c) The Author(s). 2020 Open Access This article is licensed under a Creative Commons Attribution 4.0 International License, which permits use, sharing, adaptation, distribution and reproduction in any medium or format, as long as you give appropriate credit to the original author(s) and the source, provide a link to the Creative Commons licence, and indicate if changes were made. The images or other third party material in this article are included in the article's Creative Commons licence, unless indicated otherwise in a credit line to the material. If material is not included in the article's Creative Commons licence and your intended use is not permitted by statutory regulation or exceeds the permitted use, you will need to obtain permission directly from the copyright holder. To view a copy of this licence, visit http://creativecommons.org/licenses/by/4.0/ The Creative Commons Public Domain Dedication waiver (http://creativecommons.org/publicdomain/zero/1.0/) applies to the data made available in this article, unless otherwise stated in a credit line to the data. 


\section{Background}

Mitochondrial diseases are clinically and genetically heterogeneous disorders that affect multiple organs, are characterized by impaired energy production, and can present at any age. Neurological symptoms are the most common clinical presentation and liver involvement is observed in approximately $10-20 \%$ of cases, particularly in patients that present as neonates or during early infancy [1].

Mitochondrial DNA depletion syndrome (MTDPS) is caused by defects in any of the proteins involved in mtDNA maintenance, leading to quantitative and qualitative defects in mtDNA, and currently has been classified as mtDNA maintenance defects [2, 3]. MTDPS has three clinical phenotypes; myopathic, encephalomyopathic, and hepatocerebral. Hepatocerebral MTDPS is known to cause acute liver failure in infancy and is associated with mutations in DGUOK, MPV17, POLG, SUCLG1, and TWNK [4].

Liver transplantation (LT) is considered as a definitive treatment option for pediatric patients with liver failure, and the survival rate for pediatric LT recipients in Japan is more than $85 \%$ at 5 years [5]. Contrarily, previous studies have reported that the overall survival rate of LT performed for mitochondrial hepatopathies was only $30 \%$ due to post-LT deterioration of neurologic and extrahepatic symptoms [6]. LT for mitochondrial diseases may be considered in patients with isolated liver disease, however, it is difficult to exclude the development or deterioration of extrahepatic manifestation before LT in a clinical setting.

In 2013, we reported the clinical and molecular characteristics of MTDPS in Japan [7], identifying 13 patients with hepatocerebral MTDPS. Among those patients, mutations in $D G U O K$ were the most frequently observed followed by MPV17 and POLG. Since that earlier report, we have diagnosed ten additional patients with hepatocerebral MTDPS and have performed LT on patients with mitochondrial hepatopathies [8-10]. The purposes of this study were to clarify the current clinical and molecular features of hepatocerebral MTDPS and to evaluate the outcomes of LT in MTDPS patients in Japan.

\section{Methods}

We performed a retrospective review of patients who were diagnosed with hepatocerebral MTDPS from 2007 to 2019. Patients were enzymatically and/or genetically diagnosed and diagnosis of MTDPS was confirmed by quantitative polymerase chain reaction (qPCR). This study was approved by the ethics boards of Chiba Children's Hospital and Saitama Medical University.

\section{Patients}

We have used biochemical and molecular genetic testing to diagnose mitochondrial diseases in Japan since 2007.
A total of 999 patients were diagnosed with mitochondrial diseases, 101 (10.1\%) of which were mitochondrial hepatopathies. Among these, 23 patients were diagnosed with hepatocerebral MTDPS.

\section{Mitochondrial respiratory chain enzyme activity}

We examined mitochondrial respiratory chain enzyme activity using liver samples as previously described [11]. Enzymatic diagnosis was confirmed according to the diagnostic criteria described by Bernier et al. [12]

\section{Quantitative polymerase chain reaction}

Nuclear DNA and mtDNA were enumerated by qPCR, according to the previously described methods [7, 13]. The mtDNA gene ND1 was compared against a nuclear reference gene, exon 24 of CFTR. A relative copy number of mtDNA to nuclear DNA of $<35 \%$ was defined as mtDNA depletion.

\section{Results \\ Clinical characteristics}

Table 1 shows the clinical characteristics of the patients. The cohort comprised 23 patients (11 male and 12 female) with hepatocerebral MTDPS from 19 nonconsanguineous families; 15 of the patients have been reported earlier $[3,7,8,10]$. Twenty patients $(87 \%)$ presented with initial manifestations during infancy, and six of those developed initial symptoms during the neonatal period. The most common initial manifestation was failure to thrive, seen in 13 patients (56.5\%), followed by vomiting ( $8 / 23$ patients), and jaundice ( $4 / 23$ patients). Mitochondrial respiratory chain enzymes were analyzed in 22 of the patients, and multiple enzyme deficiencies in liver tissues were noted in 19. All affected patients tested for mtDNA content showed significant mtDNA depletion, ranging from 0.5 to $31.7 \%$. Causative genes were identified in 18 of the 23 hepatocerebral MTDPS patients. Liver manifestations are shown in Table 2. The most frequently observed liver symptom was cholestasis (21/23 patients, 91.3\%); meanwhile hepatomegaly, fatty liver, liver fibrosis, and liver failure were observed in 15 (68.2\%), 16 (72.7\%), 17 (77.2\%), and 20 patients (87.0\%), respectively. Furthermore, hepatocellular carcinoma (HCC) developed in two patients with MPV17 deficiency, and the level of $\alpha$-fetoprotein was highly variable, ranging from 24.9 to $503,320 \mathrm{ng} / \mathrm{mL}$.

Table 3 shows the breakdown of extrahepatic manifestations. Failure to thrive $(18 / 21)$ was the most common extrahepatic involvement. Vomiting (10/22) and feeding difficulties $(11 / 23)$, which developed during the neonatal period, were also frequent symptoms. Hypoglycemia and lactic acidosis were found in 15 and 16 patients, respectively. Pulmonary hypertension (PH) was observed in $5 /$ 22 patients (MPV17, four patients [Pt936, Pt1244, 
Table 1 Clinical characteristics of 23 hepatocerebral MTDPS patients

\begin{tabular}{|c|c|c|c|c|c|c|c|c|}
\hline ID & Gene & Sex & $\begin{array}{l}\text { Gestational } \\
\text { age }\end{array}$ & $\begin{array}{l}\text { Birth weight } \\
\text { (SD) }\end{array}$ & $\begin{array}{l}\text { Age at } \\
\text { onset }\end{array}$ & Initial manifestations & $\begin{array}{l}\text { Affected } \\
\text { complex in Liver }\end{array}$ & $\begin{array}{l}\text { \%mtDNA in } \\
\text { Liver }\end{array}$ \\
\hline Pt68EB & MPV17 & M & $37 w 0 d$ & $3060 \mathrm{~g}(1.0 \mathrm{SD})$ & $3 \mathrm{~m}$ & failure to thrive, hypotonia, jaundice & $\mathrm{Cl}+\mathrm{III}+\mathrm{IV}$ & 7.8 \\
\hline Pt68YB & MPV17 & M & $40 \mathrm{w} 0 \mathrm{~d}$ & $3260 \mathrm{~g}(0.1 \mathrm{SD})$ & $8 \mathrm{~m}$ & failure to thrive, jaundice & $\mathrm{Cl}+\mathrm{III}+\mathrm{IV}$ & 6.6 \\
\hline Pt292 & MPV17 & $\mathrm{F}$ & $40 w 5 d$ & $3428 \mathrm{~g}(1.0 \mathrm{SD})$ & $1 \mathrm{~m}$ & failure to thrive, vomiting & $\mathrm{Cl}+\mathrm{III}$ & 9.8 \\
\hline Pt339 & MPV17 & $\mathrm{F}$ & NA & NA & $8 \mathrm{~m}$ & failure to thrive & $\mathrm{Cl}+\mathrm{III}$ & 20.5 \\
\hline Pt936 & MPV17 & M & $38 \mathrm{w} 0 \mathrm{~d}$ & $3240 \mathrm{~g}(1.3 \mathrm{SD})$ & $1 \mathrm{~m}$ & failure to thrive & $\mathrm{Cl}+\mathrm{III}+\mathrm{IV}$ & 8.0 \\
\hline Pt1244 & MPV17 & M & $40 \mathrm{w} 0 \mathrm{~d}$ & $2909 \mathrm{~g}(-0.9$ SD) & $1 \mathrm{~m}$ & failure to thrive & $\mathrm{Cl}+\mathrm{III}+\mathrm{IV}$ & 1.2 \\
\hline Pt1273 & MPV17 & $\mathrm{F}$ & $39 \mathrm{w} 0 \mathrm{~d}$ & $3010 \mathrm{~g}(0.1 \mathrm{SD})$ & $1 \mathrm{~m}$ & failure to thrive, vomiting & $\mathrm{Cl}+\mathrm{III}+\mathrm{IV}$ & 3.4 \\
\hline Pt1702 & MPV17 & M & NA & NA & neonate & failure to thrive, vomiting & NA & NA \\
\hline Pt1943 & MPV17 & M & $37 w 5 d$ & $2692 \mathrm{~g}(-0.5 \mathrm{SD})$ & neonate & tachypnea, jaundice & $\mathrm{Cl}+\mathrm{III}$ & 0.5 \\
\hline Pt2017EB & MPV17 & M & $38 \mathrm{w} 0 \mathrm{~d}$ & $2950 \mathrm{~g}(0.5 \mathrm{SD})$ & $7 m$ & liver failure & $\mathrm{Cl}+\mathrm{III}$ & 0.7 \\
\hline Pt2017YS & MPV17 & $\mathrm{F}$ & $37 w 6 d$ & $2830 \mathrm{~g}(0.1 \mathrm{SD})$ & $1 y$ & vomiting, lethargy & $\mathrm{Cl}+\mathrm{IV}$ & 7.1 \\
\hline Pt2017ES & MPV17 & $\mathrm{F}$ & $38 \mathrm{w} 0 \mathrm{~d}$ & $2728 \mathrm{~g}(0.1 \mathrm{SD})$ & 4 y $5 \mathrm{~m}$ & vomiting, lethargy & $\mathrm{Cl}+\mathrm{III}+\mathrm{IV}$ & 0.6 \\
\hline Pt2170 & MPV17 & $\mathrm{F}$ & $36 w 2 d$ & $2428 \mathrm{~g}(0 \mathrm{SD})$ & $7 \mathrm{~m}$ & failure to thrive, cholestasis, liver dysfunction & $\mathrm{Cl}+\mathrm{III}+\mathrm{IV}$ & 15.3 \\
\hline Pt50YS & DGUOK & $\mathrm{F}$ & $40 w 2 d$ & $2750 \mathrm{~g}(-1.2 \mathrm{SD})$ & neonate & tachypnea, hypothermia, hypoglycemia & $\mathrm{Cl}+\mathrm{III}+\mathrm{IV}$ & 6.0 \\
\hline Pt50ES & DGUOK & $\mathrm{F}$ & $40 \mathrm{w} 0 \mathrm{~d}$ & $2510 \mathrm{~g}(-1.5 \mathrm{SD})$ & $3 \mathrm{~m}$ & failure to thrive, incomplete head control & $\mathrm{Cl}+\mathrm{III}+\mathrm{IV}$ & 3.0 \\
\hline Pt66 & DGUOK & $\mathrm{F}$ & $37 w 3 d$ & $1688 \mathrm{~g}(-3.2 \mathrm{SD})$ & neonate & feeding difficulty & $\mathrm{Cl}+\mathrm{III}+\mathrm{IV}$ & 2.3 \\
\hline Pt74 & POLG & $\mathrm{F}$ & $40 \mathrm{w} 0 \mathrm{~d}$ & normal & $4 \mathrm{~m}$ & failure to thrive, lethargy, hypotonia, vomiting & $\mathrm{Cl}+\mathrm{III}+\mathrm{IV}$ & 3.3 \\
\hline Pt94 & MICOS13 & $\mathrm{F}$ & $40 w 3 d$ & $2780 \mathrm{~g}(-0.8 \mathrm{SD})$ & $3 \mathrm{~m}$ & breath holding & $\mathrm{Cl}$ & 11.5 \\
\hline Pt63 & ND & M & $37 w 0 d$ & $1884 \mathrm{~g}(-2.5 \mathrm{SD})$ & $2 m$ & failure to thrive, vomiting & $\mathrm{Cl}$ & 23.7 \\
\hline Pt92 & ND & M & $40 \mathrm{w} 0 \mathrm{~d}$ & $3120 \mathrm{~g}(-0.3 \mathrm{SD})$ & $1 \mathrm{~m}$ & failure to thrive, jaundice & $\mathrm{Cl}+\mathrm{III}$ & 18.4 \\
\hline Pt148 & ND & $\mathrm{F}$ & $38 w 4 d$ & $2254 \mathrm{~g}(-1.7 \mathrm{SD})$ & neonate & vomiting & $\mathrm{Cl}$ & 31.7 \\
\hline Pt1156 & ND & M & $37 w 3 d$ & $1992 \mathrm{~g}(-2.1 \mathrm{SD})$ & neonate & hypoglycemia, lactic acidosis & $\mathrm{Cl}+\mathrm{IV}$ & 6.3 \\
\hline Pt1589 & ND & M & $23 w 5 d$ & $624 \mathrm{~g}(0 \mathrm{SD})$ & 4 y $3 \mathrm{~m}$ & elevated transaminases & $\mathrm{Cl}+\mathrm{III}+\mathrm{IV}$ & 10.6 \\
\hline
\end{tabular}

C, complex; EB, elder brother; ES, elder sister; NA, not available; ND, not detected; YB, younger brother; YS, younger sister

Pt1273, and Pt1943]; DGUOK, one patient [Pt66]). Hypothermia was also observed in one patient with DGUOK deficiency.

\section{Molecular investigations}

We identified causative genes in 18 of the 23 patients, including mutations in MPV17 (13 patients), DGUOK (3 patients), POLG (one patient) and MICOS13 (one patient). The variants that are predicted to be pathogenic are presented in Table 4. Homozygous or compound heterozygous c.451dupC (p.L151Pfs*39) with other mutations were detected in 8 of 13 MPV17 deficient patients. The c.143-307_170del335 mutation was found in all three patients with DGUOK deficiency. Pt94 had a novel homozygous frameshift mutation, c.13_29del (p.W6Pfs*71) in MICOS13.

\section{Liver transplantation and prognosis}

LT from a living donor was performed on 12 patients, including nine with MPV17 deficiency and two with DGUOK deficiency (Table 4). The reasons for performing LT were as follows: two patients (Pt68YB and
Pt2017ES) had HCC, two patients (Pt2017EB and Pt2017YS) had multiple hepatic masses and end-stage liver disease, and the remainder of the patients had liver failure. Neurological manifestations were also observed before LT in nine patients other than Pt1702, Pt2017YS, and Pt2017ES. Furthermore, five of the 12 LT patients (41.7\%) survived, four of which were MPV17-deficient patients (Pt1702, Pt2017EB, Pt2017YS, and Pt2017ES). Three of the four patients who presented with onset after 6 months of age (75\%) survived, whereas only two of the eight patients with onset before 5 months (25\%) survived. Moreover, Pt2017YS and Pt2017ES with MPV17 deficiency did not develop any complications following LT, whereas Pt2017EB, who had mild intellectual disability before LT, presented with mild headache after LT. Lastly, Pt1702 who received LT due to liver failure at the age of 8 months had normal liver function after LT, however, developed epilepsy, mild intellectual disability, dysarthria, fine motor dysfunction, white matter lesion in magnetic resonance imaging of the brain, and psychosis after 6 years of age. 
Table 2 Liver manifestations in 23 hepatocerebral MTDPS patients

\begin{tabular}{|c|c|c|c|c|c|c|c|c|}
\hline ID & Gene & Cholestasis & Hepatomegaly & Fatty liver & Fibrosis & Liver failure & Tumor & AFP $(n g / m L)$ \\
\hline Pt68EB & MPV17 & + & + & + & + & + & - & NA \\
\hline Pt68YB & MPV17 & + & - & + & + & - & $\mathrm{HCC}$ & 24,000 \\
\hline Pt292 & MPV17 & + & + & + & - & + & - & 219,980 \\
\hline Pt339 & MPV17 & + & + & + & + & + & - & 24.9 \\
\hline Pt936 & MPV17 & + & + & + & + & + & - & 315,521 \\
\hline Pt1244 & MPV17 & + & + & + & + & + & - & 503,320 \\
\hline Pt1273 & MPV17 & + & + & + & + & + & - & 93,619 \\
\hline Pt1702 & MPV17 & + & - & + & + & + & - & NA \\
\hline Pt1943 & MPV17 & + & + & - & - & + & - & NA \\
\hline Pt2017EB & MPV17 & + & + & + & + & + & multiple hepatic nodules & 413 \\
\hline Pt2017YS & MPV17 & + & - & + & - & + & multiple hepatic nodules & 3078 \\
\hline Pt2017ES & MPV17 & + & - & + & + & - & $\mathrm{HCC}$ & 1332 \\
\hline Pt2170 & MPV17 & + & + & + & + & + & - & 60,500 \\
\hline Pt50YS & DGUOK & + & + & - & - & + & - & NA \\
\hline Pt50ES & DGUOK & - & - & - & - & + & - & NA \\
\hline Pt66 & DGUOK & + & - & + & + & + & - & NA \\
\hline Pt74 & POLG & + & + & + & + & + & - & NA \\
\hline Pt94 & MICOS13 & + & + & + & + & + & - & NA \\
\hline Pt63 & ND & + & + & - & + & + & - & 200,000 \\
\hline Pt92 & ND & + & + & - & + & + & - & $>50,000$ \\
\hline Pt148 & ND & + & - & - & + & + & - & 8400 \\
\hline Pt1156 & ND & + & + & + & + & + & - & NA \\
\hline Pt1589 & ND & - & NA & NA & NA & - & - & NA \\
\hline
\end{tabular}

AFP, a-fetoprotein; EB, elder brother; ES, elder sister; HCC, hepatocellular carcinoma; NA, not available; ND, not detected; YB, younger brother; YS, younger sister

Following LT, three MPV17-deficient patients (Pt936, Pt1244, and Pt1273) and one DGUOK-deficient patient (Pt66) developed $\mathrm{PH}$, as did one MPV17-deficient patient (Pt1943) that did not undergo LT. All five patients suffering from $\mathrm{PH}$ showed poor prognosis. The causes of death after LT were respiratory failure due to sepsis in Pt936, PH in Pt1244 and heart failure in Pt1273. Tissue vulnerability following LT caused a ruptured suture in Pt68EB, who developed peritonitis and sepsis. Pt68YB died of sepsis and acute respiratory distress syndrome caused by pneumonia after LT.

Two of the 11 patients (Pt339 and Pt1589) who did not receive LT survived. Pt 339 with MPV17 deficiency survived for 11 years after the onset of MTDPS. She presented with failure to thrive since infancy, and developed liver failure accompanied by acute encephalopathy at the age of 2 years. The liver failure was ameliorated by medical management, however, her liver disease gradually progressed to cirrhosis causing esophageal varices, which were treated by endoscopic variceal ligation. She ultimately developed certain neurological manifestations: spastic gait, intellectual disability, and seizure. At the time of writing this report, she had spastic paralysis associated with white matter lesion, and required the use of a wheelchair.

Among eight MPV17-deficient patients who harbored a frameshift mutation (c.451dupC) in at least one allele, only one patient (Pt1702) survived. All of the patients with MPV17 mutations who survived had either c.149G $>$ A, or c. $293 \mathrm{C}>\mathrm{T}$ in at least one allele. Pt339 and Pt1702, both with c.293C $>\mathrm{T}$, developed neurological symptoms, including seizures, intellectual disability, and psychiatric symptoms, while sibling patients with c.149G > A did not exhibit neurological manifestations, other than mild intellectual disability and headaches for Pt2017EB.

\section{Discussion}

Mutations in MPV17 were the most common genetic cause of MTDPS in the patient cohort involved in this study, followed by mutations in DGUOK. The prevalence of these mutations in MTDPS patients observed in our study differs from that of other studies. For example, a previous study reported that POLG mutations, 
Table 3 Extrahepatic manifestations in hepatocerebral MTDPS patients $(n=23)$

\begin{tabular}{|c|c|c|c|c|c|c|c|c|c|c|c|c|c|c|c|c|c|c|c|c|c|}
\hline \multirow[t]{2}{*}{ ID } & \multirow[t]{2}{*}{ Gene } & \multicolumn{10}{|c|}{ Neuromuscular } & \multicolumn{3}{|c|}{ Gastrointestinal } & \multicolumn{4}{|c|}{ Metabolism } & \multicolumn{3}{|c|}{ Others } \\
\hline & & DD & Hy & $\mathrm{Sz}$ & Ny & SG & Id & Psy & FMD & Dy & WML & $\mathrm{FD}$ & Vo & $\mathrm{Di}$ & $\mathrm{FTT}$ & $\mathrm{Hg}$ & LA & $\mathrm{Ht}$ & $\mathrm{PH}$ & $\mathrm{CM}$ & Ur \\
\hline Pt68EB & MPV17 & + & + & - & - & - & - & - & - & - & - & + & + & + & + & - & - & - & - & - & - \\
\hline Pt68YB & MPV17 & - & + & - & - & - & - & - & - & - & - & - & - & - & + & - & + & - & - & - & - \\
\hline Pt292 & MPV17 & - & - & - & - & - & - & - & - & - & + & + & + & + & + & + & + & - & - & + & - \\
\hline Pt339 & MPV17 & - & - & + & - & + & + & - & - & - & + & - & - & - & + & + & + & - & - & - & - \\
\hline Pt936 & MPV17 & + & + & - & - & - & - & - & - & - & - & + & + & + & + & + & + & - & + & - & - \\
\hline Pt1244 & MPV17 & + & + & + & - & - & - & - & - & - & - & + & - & - & + & + & + & - & + & - & - \\
\hline Pt1273 & MPV17 & + & - & - & - & - & - & - & - & - & NA & + & + & - & + & + & + & - & + & - & + \\
\hline Pt1702 & MPV17 & - & - & + & - & - & + & + & + & + & + & - & - & - & + & + & + & - & - & - & - \\
\hline Pt1943 & MPV17 & + & + & - & - & - & - & - & - & - & - & + & - & - & + & + & + & - & + & - & - \\
\hline Pt2017EB & MPV17 & + & - & - & - & - & + & - & - & - & - & - & + & - & - & + & - & - & - & - & - \\
\hline Pt2017YS & MPV17 & - & - & - & - & - & - & - & - & - & - & - & + & - & - & + & - & - & - & - & - \\
\hline Pt2017ES & MPV17 & - & - & - & - & - & - & - & - & - & - & - & + & - & - & + & - & - & - & - & - \\
\hline Pt2170 & MPV17 & + & - & + & - & + & - & - & - & - & + & + & - & + & + & + & + & - & - & - & - \\
\hline Pt50YS & DGUOK & - & - & - & - & - & - & - & - & - & NA & - & - & - & NA & + & + & + & - & - & - \\
\hline Pt50ES & DGUOK & + & + & - & + & - & - & - & - & - & NA & - & - & - & + & NA & NA & - & - & - & - \\
\hline Pt66 & DGUOK & + & + & - & + & - & - & - & - & - & NA & + & - & - & + & - & + & - & + & - & - \\
\hline Pt74 & $P O L G$ & + & + & - & - & - & - & - & - & - & - & + & + & + & + & - & + & - & - & - & - \\
\hline Pt94 & MICOS13 & - & - & - & - & - & - & - & - & - & - & + & - & - & + & - & + & - & - & - & - \\
\hline Pt63 & ND & + & - & - & - & - & - & - & - & - & - & - & + & - & + & + & - & - & - & - & - \\
\hline Pt92 & ND & - & - & - & - & - & - & - & - & - & NA & - & - & - & + & - & NA & - & - & - & - \\
\hline Pt148 & ND & - & - & - & - & - & - & - & - & - & + & + & + & - & + & + & + & - & - & - & - \\
\hline Pt1156 & ND & + & - & - & - & - & - & - & - & - & NA & - & - & - & + & + & + & - & - & - & - \\
\hline \multirow[t]{2}{*}{ Pt1589 } & ND & + & NA & - & NA & NA & NA & NA & NA & NA & NA & - & NA & NA & NA & NA & + & - & NA & NA & NA \\
\hline & Total & $\begin{array}{l}13 / \\
23\end{array}$ & $\begin{array}{l}8 / \\
22\end{array}$ & $\begin{array}{l}4 / \\
23\end{array}$ & $\begin{array}{l}21 \\
22\end{array}$ & $\begin{array}{l}21 \\
22\end{array}$ & $\begin{array}{l}3 / \\
22\end{array}$ & $\begin{array}{l}1 / \\
22\end{array}$ & $1 / 22$ & $\begin{array}{l}1 / \\
22\end{array}$ & $5 / 16$ & $\begin{array}{l}11 / \\
23\end{array}$ & $\begin{array}{l}10 / \\
22\end{array}$ & $\begin{array}{l}5 / \\
22\end{array}$ & $\begin{array}{l}18 / \\
21\end{array}$ & $\begin{array}{l}15 / \\
21\end{array}$ & $\begin{array}{l}16 / \\
21\end{array}$ & $\begin{array}{l}1 / \\
23\end{array}$ & $\begin{array}{l}5 / \\
22\end{array}$ & $\begin{array}{l}1 / \\
22\end{array}$ & $\begin{array}{l}1 / \\
22\end{array}$ \\
\hline
\end{tabular}

CM, cardiomyopathy; DD, developmental delay; Di, diarrhea; Dy, dysarthria; EB, elder brother; $E S$, elder sister; $F D$, feeding difficulties; $F M D$, fine motor dysfunction; $\mathrm{FTT}$, failure to thrive; $\mathrm{Hg}$, hypoglycemia; $\mathrm{Ht}$, hypothermia; $\mathrm{Hy}$, hypotonia; Id, intellectual disability; LA, lactic acidosis; NA, not available; ND, not detected; $\mathrm{Ny}$, nystagmus; PH, pulmonary hypertension; Psy, psychosis; SG, spastic gait; Sz, seizure; Ur, urolithiasis; Vo, vomiting; WML, white matter lesion; YB, younger brother; YS, younger sister

followed by MPV17 and DGUOK mutations, were the most common in European countries [14]. Meanwhile, another showed that MPV17 and DGUOK were the most, and second most, frequent genetic causes of MTDPS, respectively [15], although all parents of the patients in that study were consanguineous.

Whole exome sequencing identified a homozygous c.13_29del in MICOS13, in Pt94. This novel mutation caused reduced levels of MICOS13 mRNA and protein in the patient's fibroblasts and was confirmed by a rescue assay using a lentivirus system. Although MICOS13 has not been reported to be directly involved in mitochondrial DNA replication, several reports support this relationship. For example, IMMT (also known as MIC60 or Mitofilin) has a critical role in MICOS assembly and mitochondrial DNA organization [16]. IMMT directly contacts mtDNA and is involved in the D-loop architecture. Other studies showed that a defect in $\mathrm{CHCHD10}$, which is also related to MICOS complex function, resulted in decreased MICOS complex organization, reduced copy number and caused instability of mtDNA $[17,18]$.

The frameshift mutation c.451dupC was seen in 8 of 13 patients (61.5\%) in our cohort with MPV17 deficiency. A homozygous c.451dupC mutation was also identified in Korean sibling patients who died from liver failure at the age of 6 months [19], however, has not reported elsewhere. Japanese patients with the homozygous c.451dupC also developed liver failure requiring LT during infancy and died within 2 years of LT. It is, therefore, conceivable that the c.451dupC mutation might be more frequent in East Asian populations, and homozygosity at this locus is likely associated with poor outcomes regardless of whether LT is performed. In 
Table 4 Identified gene mutations in patients, liver transplantation status, and clinical outcomes

\begin{tabular}{|c|c|c|c|c|c|c|}
\hline ID & Gene & Allele 1 & Allele 2 & Age at onset & LT (age) & Outcome \\
\hline Pt68EB & MPV17 & c.451dupC: p.L151Pfs*39 & c.509C > T: p.S170F & $3 \mathrm{~m}$ & $+(1$ y 5 m) & died (1 y $10 \mathrm{~m})$ \\
\hline Pt68YB & MPV17 & c.451dupC: p.L151Pfs*39 & c.509C > T: p.S170F & $8 \mathrm{~m}$ & $+(6 y)$ & died (6 y) \\
\hline Pt292 & MPV17 & c.451dupC: p.L151Pfs*39 & c.148C > T: p.R50W & $1 \mathrm{~m}$ & - & died (1 y 2 m) \\
\hline Pt339 & MPV17 & c.293C > T: p.P98L & $c .376-1 G>A$ & $8 m$ & - & alive (12 y) \\
\hline Pt936 & MPV17 & c.451dupC: p.L151Pfs*39 & c.451dupC: p.L151Pfs*39 & $1 \mathrm{~m}$ & $+(4 \mathrm{~m})$ & died (1 y 9 m) \\
\hline Pt1244 & MPV17 & c.451dupC: p.L151Pfs*39 & c.451dupC: p.L151Pfs*39 & $1 \mathrm{~m}$ & $+(11 \mathrm{~m})$ & died (2 y 9 m) \\
\hline Pt1273 & MPV17 & c.451dupC: p.L151Pfs*39 & c.71-2_79del11 ins4 & $1 \mathrm{~m}$ & $+(1 \mathrm{y})$ & died (3 y) \\
\hline Pt1702 & MPV17 & c.451dupC: p.L151Pfs*39 & c.293C > T: p.P98L & neonate & $+(8 \mathrm{~m})$ & alive (23 y) \\
\hline Pt1943 & MPV17 & c.451dupC: p.L151Pfs*39 & c.308_310del: p.C103del & neonate & - & died $(10 \mathrm{~m})$ \\
\hline Pt2017EB & MPV17 & C.148C > T: p.R50W & c.149G > A: p.R50Q & $7 \mathrm{~m}$ & $+(7 \mathrm{y})$ & alive (8 y) \\
\hline Pt2017YS & MPV17 & c.148C > T: p.R50W & c.149G > A: p.R50Q & $1 y$ & $+(5 y)$ & alive (5 y) \\
\hline Pt2017ES & MPV17 & c. $148 \mathrm{C}>\mathrm{T}: \mathrm{p} . \mathrm{R} 50 \mathrm{~W}$ & c.149G > A: p.R50Q & 4 y $5 \mathrm{~m}$ & $+(7 y)$ & alive $(8 \mathrm{y})$ \\
\hline Pt2170 & MPV17 & c.148C > T: p.R50W & c.271_273del: p.L91del & $7 \mathrm{~m}$ & - & died (1 y $11 \mathrm{~m}$ ) \\
\hline Pt50YS & DGUOK & c.143-307_170del335 & c.143-307_170del335 & neonate & - & died (9 m) \\
\hline Pt50ES & DGUOK & c.143-307_170del335 & c.143-307_170del335 & $3 \mathrm{~m}$ & $+(1$ y 6 m) & died (1 y 7 m) \\
\hline Pt66 & DGUOK & c.143-307_170del335 & c.743 T > C: p.L248P & neonate & $+(8 \mathrm{~m})$ & died (1 y 6 m) \\
\hline Pt74 & POLG & c.3554 T > C: p.l1185T & c.2870C > T: p.A957V & $4 \mathrm{~m}$ & - & died (8 m) \\
\hline Pt94 & MICOS13 & c.13_29del: p.W6Pfs*71 & c.13_29del: p.W6Pfs*71 & $3 \mathrm{~m}$ & - & died (8 m) \\
\hline Pt63 & ND & - & - & $2 m$ & $+(9 \mathrm{~m})$ & alive (16 y) \\
\hline Pt92 & ND & - & - & $1 \mathrm{~m}$ & - & died (7 m) \\
\hline Pt148 & ND & - & - & neonate & - & died (1 m) \\
\hline Pt1156 & ND & - & - & neonate & - & died (7 m) \\
\hline Pt1589 & ND & - & - & 4 y 3 m & - & alive (6 y) \\
\hline
\end{tabular}

MPV17: NM_002437, DGUOK: NM_080918, POLG: NM_002693, MICOS13: NM_205767

$E B$ elder brother, ES elder sister, $L T$ liver transplantation, ND not detected, YB younger brother, YS younger sister, * Stop codon

contrast, two patients with c.293C $>\mathrm{T}$ and sibling patients with c.149G > A, in which homozygosity is associated with a comparatively better prognosis, survived regardless of LT $[3,20]$. Taken together, patients harboring c.149G > A or c.293C $>\mathrm{T}$ in at least one MPV17 allele of might show milder phenotypes.

LT in patients with mitochondrial diseases remains controversial due to the potential for extrahepatic manifestations. In guidelines for pediatric patients, LT for patients with mitochondrial diseases involving severe and life-threatening extrahepatic multi organ manifestations is contraindicated due to the high possibility of neurological deterioration [21]. In such patients, limited data are available regarding the efficacy of LT and long-term prognosis, and outcomes are known to be heterogenous $[1,22-24]$. It has been reported that five of 14 patients with $D G U O K$ mutations survived for more than 5 years after LT without severe neurological symptoms, even though some patients presented with muscle hypotonia and psychomotor retardation before transplantation [22]. In that study, all survivors harbored at least one mutation that predicted a DGUOK protein with some potential residual activity. Moreover, in our cohort, overall survival rate following LT for MTDPS was 41.7\%, which was lower than that for other diseases $(>85 \%)$ [5]. We also found that survival rate of LT patients with onset after 6 months of age (75\%) was higher than that of onset before 5 months (25\%). LT may, therefore, be more effective in patients with later onset.

Table 5 summarizes 20 patients with MPV17 mutations who received LT $[20,25-31]$, including nine patients from our cohort. Nine of these 20 patients (45.0\%) survived after LT. Patients with the homozygous c.149G > A, or compound heterozygous c.149G > A or c.293C $>\mathrm{T}$, with other mutations tended to show a better prognosis after LT. Eight of the 11 deceased patients (72.7\%) presented with neurological involvements before LT. Mild neurological symptoms were observed before LT in just one of the nine patients that survived, however, seven patients (77.8\%) manifested with neurological abnormalities after LT. Collectively, patients harboring c.149G $>$ A or c. $293 \mathrm{C}>\mathrm{T}$ in at least one allele without marked neurological manifestations might have a better prognosis after LT. 
Table 5 Molecular and neurological findings as well as outcomes in 20 MPV17-deficient patients who received LT

\begin{tabular}{|c|c|c|c|c|c|c|c|c|}
\hline & \multirow[t]{2}{*}{ Sex } & \multirow[t]{2}{*}{ Allele 1} & \multirow[t]{2}{*}{ Allele 2} & \multirow{2}{*}{$\begin{array}{l}\text { Age at } \\
\text { onset }\end{array}$} & \multicolumn{2}{|l|}{ Neurological findings } & \multirow{2}{*}{$\begin{array}{l}\mathrm{LT} \\
\text { age }\end{array}$} & \multirow[t]{2}{*}{ Outcome } \\
\hline & & & & & Before LT & After LT & & \\
\hline Pt68EB & M & $\begin{array}{l}\text { c.451dupC: } \\
\text { p.L151Pfs*39 }\end{array}$ & $\begin{array}{l}\text { c. } 509 C>T: \\
\text { p.S170F }\end{array}$ & $3 \mathrm{~m}$ & hypotonia & + & $\begin{array}{l}17 \\
m\end{array}$ & $\begin{array}{l}\text { died } \\
(1 \text { y } 10 \mathrm{~m})\end{array}$ \\
\hline Pt68YB & M & $\begin{array}{l}\text { c.451dupC: } \\
\text { p.L151Pfs*39 }\end{array}$ & $\begin{array}{l}\text { c. } 509 \mathrm{C}>\mathrm{T}: \\
\text { p.S170F }\end{array}$ & $8 \mathrm{~m}$ & hypotonia & + & $6 y$ & died $(6 y)$ \\
\hline Pt936 & M & $\begin{array}{l}\text { c.451dupC: } \\
\text { p.L151Pfs*39 }\end{array}$ & $\begin{array}{l}\text { c.451dupC: } \\
\text { p.L151Pfs*39 }\end{array}$ & $1 \mathrm{~m}$ & $\begin{array}{l}\text { developmental delay, } \\
\text { hypotonia }\end{array}$ & + & $4 \mathrm{~m}$ & $\begin{array}{l}\text { died } \\
(1 \text { y } 9 \mathrm{~m})\end{array}$ \\
\hline Pt1244 & M & $\begin{array}{l}\text { C.451dupC: } \\
\text { p.L151Pfs*39 }\end{array}$ & $\begin{array}{l}\text { c.451dupC: } \\
\text { p.L151Pfs*39 }\end{array}$ & $1 \mathrm{~m}$ & $\begin{array}{l}\text { developmental delay, } \\
\text { hypotonia }\end{array}$ & + & $\begin{array}{l}11 \\
m\end{array}$ & $\begin{array}{l}\text { died } \\
\text { (2 y } 9 \mathrm{~m})\end{array}$ \\
\hline Pt1273 & $\mathrm{F}$ & $\begin{array}{l}\text { c.451dupC: } \\
\text { p.L151Pfs*39 }\end{array}$ & $\begin{array}{l}\text { c.71-2_- } \\
\text { 79del11ins4 }\end{array}$ & $1 \mathrm{~m}$ & developmental delay & + & $1 \mathrm{y}$ & died (3 y) \\
\hline Pt1702 & M & $\begin{array}{l}\text { c.451dupC: } \\
\text { p.L151Pfs*39 }\end{array}$ & $\begin{array}{l}\text { c.293C }>\mathrm{T}: \\
\text { p.P98L }\end{array}$ & neonate & - & $\begin{array}{l}\text { psychosis, intellectual disability, } \\
\text { fine motor dysfunction, dysarthria }\end{array}$ & $8 m$ & $\begin{array}{l}\text { alive } \\
(23 \mathrm{y})\end{array}$ \\
\hline Pt2017EB & M & $\begin{array}{l}\text { C. } 148 \mathrm{C}>\mathrm{T}: \\
\text { p.R50W }\end{array}$ & $\begin{array}{l}\text { C.149G > A: } \\
\text { p.R50Q }\end{array}$ & $7 \mathrm{~m}$ & $\begin{array}{l}\text { mild intellectual } \\
\text { disability }\end{array}$ & mild headache & $7 y$ & alive $(8 \mathrm{y})$ \\
\hline Pt2017YS & $\mathrm{F}$ & $\begin{array}{l}\text { c. } 148 \mathrm{C}>\mathrm{T} \text { : } \\
\text { p.R50W }\end{array}$ & $\begin{array}{l}\text { c. } 149 \mathrm{G}>\mathrm{A}: \\
\text { p.R50Q }\end{array}$ & $1 \mathrm{y}$ & - & - & $5 y$ & alive $(5 \mathrm{y})$ \\
\hline Pt2017ES & $\mathrm{F}$ & $\begin{array}{l}\text { C. } 148 \mathrm{C}>\mathrm{T}: \\
\text { p.R50W }\end{array}$ & $\begin{array}{l}\text { c. } 149 G>A: \\
\text { p.R50Q }\end{array}$ & 4 y $5 \mathrm{~m}$ & - & - & $7 y$ & alive (8 y) \\
\hline $\begin{array}{l}\text { Parini } \\
2009\end{array}$ & M & $\begin{array}{l}\text { c. } 149 \mathrm{G}>\mathrm{A}: \\
\text { p.R50Q }\end{array}$ & $\begin{array}{l}\text { c. } 149 \mathrm{G}>\mathrm{A}: \\
\text { p.R50Q }\end{array}$ & $1 \mathrm{~m}$ & - & $\begin{array}{l}\text { developmental delay, ataxia, severe } \\
\text { motor-sensory axonal polyneuropathy }\end{array}$ & $2 y$ & alive $(6 \mathrm{y})$ \\
\hline $\begin{array}{l}\text { Karadimas } \\
2006\end{array}$ & $\mathrm{~F}$ & $\begin{array}{l}\text { c. } 149 G>A: \\
\text { p.R50Q }\end{array}$ & $\begin{array}{l}\text { C.149G > A: } \\
\text { p.R50Q }\end{array}$ & $6 \mathrm{~m}$ & - & $\begin{array}{l}\text { hypotonia, gross and fine motor delay, } \\
\text { peripheral neuropathy }\end{array}$ & $9 \mathrm{~m}$ & $\begin{array}{l}\text { alive } \\
(12 \mathrm{y})\end{array}$ \\
\hline $\begin{array}{l}\text { Karadimas } \\
2006\end{array}$ & $\mathrm{~F}$ & $\begin{array}{l}\text { C. } 149 G>A: \\
\text { p.R50Q }\end{array}$ & $\begin{array}{l}\text { c. } 149 \mathrm{G}>\mathrm{A}: \\
\text { p.R50Q }\end{array}$ & $1 \mathrm{~m}$ & $\begin{array}{l}\text { hypotonia, } \\
\text { hyporeflexia }\end{array}$ & + & $\begin{array}{l}16 \\
m\end{array}$ & died (2 y) \\
\hline $\begin{array}{l}\text { Karadimas } \\
2006\end{array}$ & $\mathrm{~F}$ & $\begin{array}{l}\text { C. } 149 G>A: \\
\text { p.R50Q }\end{array}$ & $\begin{array}{l}\text { c. } 149 \mathrm{G}>\mathrm{A}: \\
\text { p.R50Q }\end{array}$ & $4 \mathrm{~m}$ & - & peripheral neuropathy & $11 \mathrm{y}$ & $\begin{array}{l}\text { alive } \\
(21 \mathrm{y})\end{array}$ \\
\hline $\begin{array}{l}\text { Wong } \\
2007\end{array}$ & M & $\begin{array}{l}\text { c.206G > A: } \\
\text { p.W69* }\end{array}$ & $\begin{array}{l}\text { c.206G > A: } \\
\text { p.W69* }\end{array}$ & birth & - & - & $5 \mathrm{~m}$ & died (6 m) \\
\hline $\begin{array}{l}\text { Navarro } \\
2008\end{array}$ & M & $c .70+5 G>A$ & $c .70+5 G>A$ & $2 m$ & hypotonia & + & $1 y$ & died (2 y) \\
\hline $\begin{array}{l}\text { El-Hattab } \\
2010\end{array}$ & M & $\begin{array}{l}\text { c. } 262 A>G: \\
\text { p.K88E }\end{array}$ & $\begin{array}{l}\text { c. } 262 A>G: \\
\text { p.K88E }\end{array}$ & neonate & NA & developmental delay, muscle weakness & NA & $\begin{array}{l}\text { died } \\
(2.5 \mathrm{y})\end{array}$ \\
\hline $\begin{array}{l}\text { El-Hattab } \\
2010\end{array}$ & M & $\begin{array}{l}\text { c. } 485 C>A: \\
\text { p.A162D }\end{array}$ & $\begin{array}{l}\text { c.271_273del3: } \\
\text { p.L91del }\end{array}$ & infancy & NA & hypotonia & NA & alive $(4 \mathrm{y})$ \\
\hline $\begin{array}{l}\text { Mudd } \\
2012\end{array}$ & M & c.22_23insC & ND & infancy & $\begin{array}{l}\text { hypotonia, mild } \\
\text { motor delay }\end{array}$ & + & $7 y$ & died $(9$ y) \\
\hline $\begin{array}{l}\text { Uusimaa } \\
2014\end{array}$ & M & $\begin{array}{l}\text { c. } 191 C>\text { G: } \\
\text { p.P64R }\end{array}$ & $\begin{array}{l}\text { c.293C > T: } \\
\text { p.P98L }\end{array}$ & $5 \mathrm{~m}$ & - & $\begin{array}{l}\text { progressive demyelinating peripheral } \\
\text { neuropathy }\end{array}$ & $3 y$ & $\begin{array}{l}\text { alive } \\
(11.5 \mathrm{y})\end{array}$ \\
\hline $\begin{array}{l}\text { Vilarinho } \\
2014\end{array}$ & $\mathrm{~F}$ & $\begin{array}{l}\text { c. } 148 \mathrm{C}>\mathrm{T}: \\
\text { p.R50W }\end{array}$ & $\begin{array}{l}\text { c. } 148 \mathrm{C}>\mathrm{T}: \\
\text { p.R50W }\end{array}$ & $5 y$ & - & dystonia, tremor, seizure & $9 y$ & $\begin{array}{l}\text { died } \\
(10 \mathrm{y})\end{array}$ \\
\hline
\end{tabular}

EB elder brother, ES elder sister, $L T$ liver transplantation, NA not available, ND not detected, YB younger brother, $Y S$ younger sister, ${ }^{*}$ Stop codon

A previous study found that three out of 14 patients with DGUOK mutations developed PH after LT [22]. In the current study, PH was observed in five patients including four with MPV17 deficiency and one with DGUOK deficiency. Four of these developed PH after LT. Although $\mathrm{PH}$ can be caused by chronic liver disease and portal hypertension, $\mathrm{PH}$ after $\mathrm{LT}$ is infrequent; $\mathrm{PH}$ has also been reported in patients with primary mitochondrial diseases (e.g. m.3243A > G, NFU1, BOLA3) [32, 33], however, the mechanism underlying this remains unknown.

\section{Conclusions}

In conclusion, the survival rate for MTDPS patients after LT in our cohort was lower than that for other diseases, however, LT was relatively effective in patients with later onset. Our results also suggest that a better life prognosis after LT might be expected in MTDPS patients who have MPV17 mutations, such as c.149G > A or c. $293 \mathrm{C}>\mathrm{T}$, that are associated with milder phenotypes and do not have marked neurological manifestations before LT. 


\section{Abbreviations}

MTDPS: Mitochondrial DNA depletion syndrome; LT: Liver transplantation; qPCR: Quantitative polymerase chain reaction; HCC: Hepatocellular carcinoma; PH: Pulmonary hypertension

\section{Acknowledgments}

The authors thank all the patients and their doctors in charge for supplying us with data.

\section{Authors' contribution}

MS, NK and SK designed the study. MS, NK, KI and AM drafted the manuscript. NA, YS, TE, SU, Al, TF, RI, AF, M and JM collected and provided the patient data. MOT and TT performed enzyme and qPCR analyses. The whole scheme was planned and supervised by $\mathrm{YO}, \mathrm{AO}$ and KM. Professional advice on the draft was given by TF, YK, KT and KS. KM critically revised the manuscript. The authors read and approved the final manuscript.

\section{Funding}

This work was supported in part by the Practical Research Project for Rare/ Intractable Diseases from the Japan Agency for Medical Research and Development, AMED (JP19ek0109273, JP20ek0109468) to KM, SK, AO, and YO (http://www.amed.go.jp/en/) and the Project Promoting Clinical Trials for Development of New Drugs and Medical Devices, Japan Medical Association, from the Japan Agency for Medical Research and Development, AMED to AO (http://www.jmacct.med.or.jp/en/what-we-do/investigator.html). This work was also supported by an Innovative Cell Biology by Innovative Technology grant (Cell Innovation Program) from the Ministry of Education, Culture, Sports, Science and Technology (MEXT), Japan to YO (http://cellinnovation.nig.ac.jp/mext-life/english/index.html), the Support Project, and a Strategic Research Center in Private Universities grant from MEXT, Japan to Saitama Medical University Research Center for Genomic Medicine (http:// www.mext.go.jp/a_menu/koutou/shinkou/07021403/002/002/1218299.htm). This work was also supported by Grants-in-Aid of the Research on Intractable Diseases (Mitochondrial Disorder) from the Ministry of Health, Labor and Welfare of Japan, and a special research grant from Takeda Science Foundation (http://www.takeda-sci.or.jp/) to YO. The authors confirm independence from the sponsors.

\section{Availability of data and materials}

The datasets analyzed during the current study are available from the corresponding author on reasonable request.

\section{Ethics approval and consent to participate}

All procedures were performed in accordance with the ethical standards of the responsible committee on human experimentation (institutional and national) and with the Helsinki Declaration of 1975, as revised in 2000.

\section{Consent for publication}

Written informed consent was obtained from the parents of all subjects included in the study.

\section{Competing interests}

All authors declare that they have no conflict of interest

\section{Author details}

${ }^{1}$ Center for Medical Genetics, Department of Metabolism, Chiba Children's Hospital, 579-1 Heta-cho, Midori-ku, Chiba 266-0007, Japan. ${ }^{2}$ Division of Pediatrics and Perinatology, Tottori University Faculty of Medicine, 36-1 Nishi-cho, Yonago, Tottori 683-8504, Japan. ${ }^{3}$ Diagnostics and Therapeutic of Intractable Diseases, Intractable Disease Research Center, Graduate School of Medicine, Juntendo University, Hongo 2-1-1, Bunkyo-ku, Tokyo 113-8421, Japan. ${ }^{4}$ Department of Pediatric Hepatology and Gastroenterology, Saiseikai Yokohama City Tobu Hospital, 3-6-1, Shimosueyoshi, Tsurumi-ku, Yokohama, Kanagawa 230-0012, Japan. ${ }^{5}$ Department of Diagnostic Pathology, Yame General Hospital, 540-2, Takatsuka, Yame-shi, Fukuoka 834-0034, Japan. ${ }^{6}$ Department of General Pediatrics and Interdisciplinary Medicine, National Center for Child Health and Development, 2-10-1, Okura, Setagaya-ku, Tokyo 157-8535, Japan. ${ }^{7}$ Organ Transplantation Center, National Center for Child Health and Development, 2-10-1, Okura, Setagaya-ku, Tokyo 157-8535, Japan. ${ }^{8}$ Department of Pediatrics, Tsuyama Chuo Hospital, Kawasaki 1756, Tsuyama-shi, Okayama 708-0841, Japan. ${ }^{9}$ Department of Pediatrics \& Clinical
Genomics, Faculty of Medicine, Saitama Medical University, 38 Morohongo, Moroyama, Saitama 350-0495, Japan. ${ }^{10}$ Center for Intractable Diseases, Saitama Medical University Hospital, 38 Morohongo, Moroyama, Saitama 350-0495, Japan

Received: 15 March 2020 Accepted: 15 June 2020

Published online: 24 July 2020

\section{References}

1. Rahman S. Gastrointestinal and hepatic manifestations of mitochondrial disorders. J Inherit Metab Dis. 2013:36:659-73.

2. El-Hattab AW, Craigen WJ, Scaglia F. Mitochondrial DNA maintenance defects. BBA-Mol Basis Dis. 2017;1863:1539-55.

3. El-Hattab AW, Wang J, Dai H, Almannai M, Staufner C, Alfadhel M, et al. MPV17-related mitochondrial DNA maintenance defect: new cases and review of clinical, biochemical, and molecular aspects. Hum Mutat. 2018;39: 461-70.

4. El-Hattab AW, Scaglia F. Mitochondrial DNA depletion syndromes: review and updates of genetic basis, manifestations, and therapeutic options. Neurotherapeutics. 2013:10:186-98.

5. Nishimura N, Kasahara M, Ishikura K, Nakagawa S. Current status of pediatric transplantation in Japan. J Intensive Care. 2017:5:48.

6. Lee WS, Sokol RJ. Mitochondrial hepatopathies: advances in genetics, therapeutic approaches, and outcomes. J Pediatr. 2013;163:942-8.

7. Yamazaki T, Murayama K, Compton AG, Sugiana C, Harashima H, Amemiya $\mathrm{S}$, et al. Molecular diagnosis of mitochondrial respiratory chain disorders in Japan: focusing on mitochondrial DNA depletion syndrome. Pediatr Int. 2014;56:180-7.

8. Kaji S, Murayama K, Nagata I, Nagasaka H, Takayanagi M, Ohtake A, et al. Fluctuating liver functions in siblings with MPV17 mutations and possible improvement associated with dietary and pharmaceutical treatments targeting respiratory chain complex II. Mol Genet Metab. 2009;97:292-6.

9. Sasaki K, Sakamoto S, Uchida H, Narumoto S, Shigeta T, Fukuda A, et al. Liver transplantation for mitochondrial respiratory chain disorder: a singlecenter experience and excellent marker of differential diagnosis. Transpl $P$. 2017:49:1097-102.

10. Umetsu S, Inui A, Kobayashi S, Shimura M, Uehara T, Uchida H, et al. First cases of MPV17 related mitochondrial DNA depletion syndrome with compound heterozygous mutations in p.R50Q/p.R50W: a case report Hepatoma Res. 2020;6:1.

11. Kirby DM, Thorburn DR, Turnbull DM, Taylor RW. Biochemical assays of respiratory chain complex activity. Methods Cell Biol. 2007;80:93-119.

12. Bernier FP, Boneh A, Dennett X, Chow CW, Cleary MA, Thorburn DR. Diagnostic criteria for respiratory chain disorders in adults and children. Neurology. 2002:59:1406-11.

13. Pagnamenta AT, Taanman JW, Wilson CJ, Anderson NE, Marotta R, Duncan AJ, et al. Dominant inheritance of premature ovarian failure associated with mutant mitochondrial DNA polymerase gamma. Hum Reprod. 2006;21: 2467-73.

14. Spinazzola A, Invernizzi F, Carrara F, Lamantea E, Donati A, Dirocco M, et al. Clinical and molecular features of mitochondrial DNA depletion syndromes. J Inherit Metab Dis. 2009:32:143-58.

15. Al-Hussaini A, Faqeih E, El-Hattab AW, Alfadhel M, Asery A, Alsaleem B, et al. Clinical and molecular characteristics of mitochondrial DNA depletion syndrome associated with neonatal cholestasis and liver failure. J Pediatr. 2014;164:553-9.e1-2.

16. Yang RF, Sun LH, Zhang R, Zhang Y, Luo YX, Zheng W, et al. Suppression of Mic60 compromises mitochondrial transcription and oxidative phosphorylation. Sci Rep. 2015;5:7990.

17. Genin EC, Plutino M, Bannwarth S, Villa E, Cisneros-Barroso E, Roy M, et al. CHCHD10 mutations promote loss of mitochondrial cristae junctions with impaired mitochondrial genome maintenance and inhibition of apoptosis EMBO Mol Med. 2016;8:58-72.

18. Genin EC, Bannwarth S, Lespinasse F, Ortega-Vila B, Fragaki K, Itoh K, et al. Loss of MICOS complex integrity and mitochondrial damage, but not TDP43 mitochondrial localisation, are likely associated with severity of CHCHD10-related diseases. Neurobiol Dis. 2018;119:159-71.

19. Kim J, Kang E, Kim Y, Kim JM, Lee BH, Murayama K, et al. MPV17 mutations in patients with hepatocerebral mitochondrial DNA depletion syndrome. Mol Genet Metab Rep. 2016:8:74-6. 
20. Karadimas CL, Vu TH, Holve SA, Chronopoulou P, Quinzii C, Johnsen SD, et al. Navajo neurohepatopathy is caused by a mutation in the MPV17 gene. Amer J Hum Genet. 2006;79:544-8.

21. Squires RH, Ng V, Romero R, Ekong U, Hardikar W, Emre S, et al. Evaluation of the pediatric patient for liver transplantation: 2014 practice guideline by the American Association for the Study of Liver Diseases, American Society of Transplantation and the north American Society for Pediatric Gastroenterology, Hepatology and Nutrition. Hepatol. 2014;60:362-98.

22. Grabhorn E, Tsiakas K, Herden U, Fischer L, Freisinger P, Marquardt T, et al. Long-term outcomes after liver transplantation for deoxyguanosine kinase deficiency: a single-center experience and a review of the literature. Liver Transpl. 2014;20:464-72.

23. Parikh S, Karaa A, Goldstein A, Ng YS, Gorman G, Feigenbaum A, et al. Solid organ transplantation in primary mitochondrial disease: proceed with caution. Mol Genet Metab. 2016:118:178-84.

24. Parikh S, Goldstein A, Karaa A, Koenig MK, Anselm I, Brunel-Guitton C, et al. Patient care standards for primary mitochondrial disease: a consensus statement from the mitochondrial medicine society. Genet Med. 2017;19:12.

25. Uusimaa J, Evans J, Smith C, Butterworth A, Craig K, Ashley N, et al. Clinical, biochemical, cellular and molecular characterization of mitochondrial DNA depletion syndrome due to novel mutations in the MPV17 gene. Eur J Hum Genet. 2014:22:184-91.

26. Parini R, Furlan F, Notarangelo L, Spinazzola A, Uziel G, Strisciuglio P, et al. Glucose metabolism and diet-based prevention of liver dysfunction in MPV17 mutant patients. J Hepatol. 2009;50:215-21.

27. Wong $L$, Brunetti-Pierri N, Zhang Q, Yazigi N, Bove KE, Dahms BB, et al. Mutations in the MPV17 gene are responsible for rapidly progressive liver failure in infancy. Hepatol. 2007:46:1218-27.

28. Navarro-Sastre A, Martin-Hernandez E, Campos Y, Quintana E, Medina E, de Las Heras RS, et al. Lethal hepatopathy and leukodystrophy caused by a novel mutation in MPV17 gene: description of an alternative MPV17 spliced form. Mol Genet Metab. 2008;94:234-9.

29. El-Hattab AW, Li FY, Schmitt E, Zhang S, Craigen WJ, Wong LJ. MPV17associated hepatocerebral mitochondrial DNA depletion syndrome: new patients and novel mutations. Mol Genet Metab. 2010;99:300-8.

30. Mudd SH, Wagner C, Luka Z, Stabler SP, Allen RH, Schroer R, et al. Two patients with hepatic mtDNA depletion syndromes and marked elevations of Sadenosylmethionine and methionine. Mol Genet Metab. 2012;105:228-36.

31. Vilarinho S, Choi M, Jain D, Malhotra A, Kulkarni S, Pashankar D, et al. Individual exome analysis in diagnosis and management of paediatric liver failure of indeterminate aetiology. J Hepatol. 2014;61:1056-63.

32. Bray AW, Ballinger SW. Mitochondrial DNA mutations and cardiovascular disease. Curr Opin Cardiol. 2017. https://doi.org/10.1097/HCO. 0000000000000383.

33. Culley MK, Chan SY. Mitochondrial metabolism in pulmonary hypertension: beyond mountains there are mountains. J Clin Invest. 2018;128:3704-15.

\section{Publisher's Note}

Springer Nature remains neutral with regard to jurisdictional claims in published maps and institutional affiliations.

\section{Ready to submit your research? Choose BMC and benefit from:}

- fast, convenient online submission

- thorough peer review by experienced researchers in your field

- rapid publication on acceptance

- support for research data, including large and complex data types

- gold Open Access which fosters wider collaboration and increased citations

- maximum visibility for your research: over $100 \mathrm{M}$ website views per year

At $\mathrm{BMC}$, research is always in progress.

Learn more biomedcentral.com/submissions 